This is an electronic reprint of the original article. This reprint may differ from the original in pagination and typographic detail.

Author(s): Konu, Jari; Chivers, Tristram; Tuononen, Heikki

Title: $\quad$ The cyclic $[\mathrm{N}(\operatorname{PiPr} 2 \mathrm{E}) 2]+(\mathrm{E}=\mathrm{Se}, \mathrm{Te})$ cations: a new class of inorganic ring system

Year: $\quad 2006$

Version:

Please cite the original version:

Konu, J., Chivers, T., \& Tuononen, H. (2006). The cyclic [N(PiPr2E)2]+ (E = Se, Te) cations: a new class of inorganic ring system. Chemical Communications, (15), 16341636. https://doi.org/10.1039/B600040A

All material supplied via JYX is protected by copyright and other intellectual property rights, and duplication or sale of all or part of any of the repository collections is not permitted, except that material may be duplicated by you for your research use or educational purposes in electronic or print form. You must obtain permission for any other use. Electronic or print copies may not be offered, whether for sale or otherwise to anyone who is not an authorised user. 


\title{
The Cyclic $\left[N\left(\operatorname{Pi}^{i} \mathrm{Pr}_{2} E\right)_{2}\right]^{+}(E=\mathrm{Se}, \mathrm{Te})$ Cations: A New Class of Inorganic Ring System
}

\author{
Jari Konu, ${ }^{a}$ Tristram Chivers ${ }^{* a}$ and Heikki M. Tuononen ${ }^{b}$
}

The two-electron oxidation of $\left[(\operatorname{tmeda}) \mathrm{NaN}\left(\operatorname{P}^{i} \operatorname{Pr} 2 \mathrm{E}\right)_{2}\right]$ with iodine produces the cyclic $\left[\mathrm{N}\left(\mathbf{P}^{i} \operatorname{Pr}_{2} \mathbf{E}\right)_{2}\right]^{+}(\mathbf{E}=\mathrm{Se}$, Te) cations, which exhibit long $\mathrm{E}-\mathrm{E}$ bonds in the iodide salts

The coordination chemistry of the dichalcogenoimidodiphosphinate 10 ligands $\left[\mathrm{N}\left(\mathrm{PR}_{2} \mathrm{E}\right)_{2}\right]^{-} \mathbf{1}(\mathrm{E}=\mathrm{O}, \mathrm{S}, \mathrm{Se})$ has been studied extensively. ${ }^{1}$ This pervasive interest arises from a number of potential uses $e . g$., as lanthanide shift reagents, ${ }^{2}$ in luminescent materials, ${ }^{3}$ or in metal extraction processes. ${ }^{4}$ More recently, O'Brien and co-workers have shown that certain metal complexes of the isopropyl derivatives $\mathbf{1 a}$ 15 and $\mathbf{1 b}$ are sufficiently volatile to serve as single-source precursors for the production of thin semi-conducting films. ${ }^{5}$ The cadmium complex of $\mathbf{1 b}$ produces CdSe quantum dots in a solvothermal reaction. ${ }^{6}$

20<smiles>F[PH](#P)=NP=P</smiles>

$1 a(E=S)$

$1 b(E=S e)$

$1 c(E=T e)$

25

30

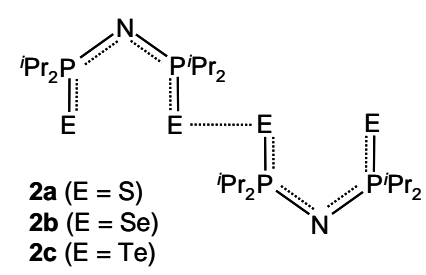

The neutral precursors to the anionic ligands $\mathbf{1 a}$ and $\mathbf{1 b}$ are readily made by direct reaction between $\mathrm{HN}\left(\mathrm{P}^{i} \mathrm{Pr}_{2}\right)_{2}$ and elemental 35 sulfur or selenium, respectively, ${ }^{7}$ but this reaction is not successful for the synthesis of $\mathrm{HN}\left(\mathrm{P}^{i} \operatorname{Pr}_{2} \mathrm{Te}\right)_{2}$. Consequently, we have developed a different approach to the synthesis of the anionic tellurium ligands $\left[\mathrm{N}\left(\mathrm{PR}_{2} \mathrm{Te}\right)_{2}\right]^{-}\left(\mathrm{R}={ }^{i} \mathrm{Pr}, \mathrm{Ph}\right)$ that involves metallation of $\mathrm{HN}\left(\mathrm{PR}_{2}\right)_{2}$ with $\mathrm{NaH}$ prior to reaction with 40 tellurium. $^{8,9}$ A fascinating feature of the chemistry of $\mathbf{1 c}$ is the formation of the unusual ditelluride $\mathbf{2 c}$ upon stoichiometric oxidation of the sodium salt with iodine..$^{8,9}$ The ditelluride $\mathbf{2 c}$ may be considered to be the dimer of the tellurium-centered radical [TePi $\left.\operatorname{Pr}_{2} \mathrm{~N}^{i} \mathrm{Pr}_{2} \mathrm{PTe}\right]^{\bullet} .{ }^{9}, 10$ The discovery of $\mathbf{2 b}^{10}$ and $\mathbf{2} \mathbf{c}^{9}$ poses the 45 intriguing question of whether the corresponding cations $\mathbf{3 b}$ and $\mathbf{3 c}$ can be prepared, thus completing the sequence of different

\footnotetext{
${ }^{a}$ Department of Chemistry, University of Calgary, Calgary, $A B, T 2 N 1 N 4$, Canada. Fax: (+1)403-289-9488; Tel: (+1)403-220-5741; E-mail:

chivers@ucalgary.ca

${ }^{b}$ Department of Chemistry, University of Jyväskylä, P.O. Box 35,

Jyväskylä, FI-40014 Finland
}

oxidation states $(-1,0,+1)$ for the dichalcogenoimidodiphosphinate ligand system. In this communication we describe the synthesis, molecular and electronic structures of the salts $\left[\mathrm{N}\left(\mathrm{P}^{i} \operatorname{Pr}_{2} \mathrm{Se}\right)_{2}\right] \mathrm{I}$ (4) ${ }_{50}$ and $\left[\mathrm{N}\left(\mathrm{P}^{i} \mathrm{Pr}_{2} \mathrm{Te}\right)_{2}\right] \mathrm{I}(\mathbf{5})$, which contain the cyclic cations $\mathbf{3 b}$ and $\mathbf{3 c}$, respectively. These formally $6 \pi$-electron cations represent a novel class of inorganic ring system ${ }^{11}$ and provide a new feature of the chemistry of dichalcogenoimidodiphosphinates.

The cations $\mathbf{3 b}$ and $\mathbf{3 c}$ are readily generated by stoichiometric 55 oxidation of either the corresponding anions $\mathbf{1 b}$ and $\mathbf{1 c}$ or, in the case of $\mathbf{3 c}$, the neutral dichalcogenide $\mathbf{2 c}$ with iodine. Thus the reactions of $\left[(\right.$ tmeda $\left.) \mathrm{NaN}\left(\mathrm{P}^{i} \mathrm{Pr}_{2} \mathrm{E}\right)_{2}\right](\mathrm{E}=\mathrm{Se}, \mathrm{Te})$ with one equivalent of $\mathrm{I}_{2}$ at $-78{ }^{\circ} \mathrm{C}$ produce the iodide salts $\mathbf{4}$ and $\mathbf{5}$ in 90 and $92 \%$ yields, respectively. The surprisingly air-stable compounds ${ }^{13}$ 60 were characterized by multinuclear NMR spectroscopy and by Xray crystallography. ${ }^{\S}$ The NMR spectra reveal inequivalent ${ }^{i} \operatorname{Pr}_{2} \mathrm{P}-$ units for both compounds. In the ${ }^{1} \mathrm{H}$ NMR spectra, two sets of doublets of doublets for the Me-groups and two sets of overlapping septets (appearing as an octet) for the $\mathrm{CH}$-hydrogens are observed.

${ }_{65}$ Consistently, the ${ }^{13} \mathrm{C}\left\{{ }^{1} \mathrm{H}\right\}$ NMR spectra show two singlets for the Me-groups and a multiplet for the $\alpha$-carbons of the ${ }^{i}$ Pr-groups arising from an AXX' spin system. ${ }^{14}$ The ${ }^{31} \mathrm{P}\left\{{ }^{1} \mathrm{H}\right\}$ NMR spectra of 4 and 5 exhibit broad singlets at 92.9 and $68.0 \mathrm{ppm}$, respectively, with broad chalcogen satellites $\left({ }^{1} J_{\mathrm{Se}, \mathrm{P}} \approx 395 \mathrm{~Hz},{ }^{1} J_{\mathrm{Te}, \mathrm{P}} \approx 1035 \mathrm{~Hz}\right)$.

70 These broad signals do not resolve into the expected two resonances (mutually coupled doublets) even at $-60{ }^{\circ} \mathrm{C}$ indicating conformational non-rigidity within the rings persists at low temperature. The ${ }^{77} \mathrm{Se}$ NMR spectrum of $\mathbf{4}$ exhibits a broad doublet at $297 \mathrm{ppm}\left({ }^{1} J_{\mathrm{Se}, \mathrm{P}} \approx 420 \mathrm{~Hz}\right)$, but the ${ }^{125} \mathrm{Te}$ NMR resonance for 5 75 could not be observed owing to the low solubility of the compound.

$\mathrm{X}$-ray crystallographic analyses revealed that $\mathbf{4}$ and $\mathbf{5}$ are comprised of five-membered $\left[\mathrm{NP}_{2} \mathrm{E}_{2}\right]^{+}$cations and an iodide counter-ion that interacts with one of the chalcogen atoms of the cation resulting in inequivalent ${ }^{i} \operatorname{Pr}_{2} \mathrm{P}$-units. The molecular structure 80 (Figure 1) and crystal packing (Figure 2) are essentially the same for 4 and 5. The compounds form infinite chains of non-planar five-membered rings linked by chalcogen-iodine interactions. The two E...I interactions show only a slight variation in 5 (3.430(1) and $3.495(1) \AA$ ), whereas the corresponding difference is more 85 pronounced in 4 (3.150(1) and 4.006(1) $\AA$ ). The Te $\cdots$ I contacts in 5 are comparable to the ionic interactions found in $\mathrm{Et}_{3} \mathrm{Te}^{+} \ldots \mathrm{I}^{-}(3.418$ $\AA)^{15}$ and in $\left\{\left[(t \mathrm{BuNH}) \mathrm{Te}^{+}(\mu-\mathrm{N} t \mathrm{Bu})_{2} \mathrm{Te}(\mu-\mathrm{O})\right]_{2}\right\} \cdots\left(\mathrm{I}^{-}\right)_{2} \quad(3.410(1)$ and 3.445(1) $\AA) .{ }^{16}$ The shorter Se $\cdots I$ interaction in $\mathbf{4}$ is somewhat longer than that observed in $\mathrm{Ph}_{2} \mathrm{Se}_{2} \mathrm{I}_{2}(2.992 \AA),{ }^{17}$ which also 90 contains a Se-Se $\cdots$ I-unit. The second Se $\cdots I$ interaction is close to the sum of van der Waals radii for selenium and iodine (4.15 $).{ }^{18}$ 


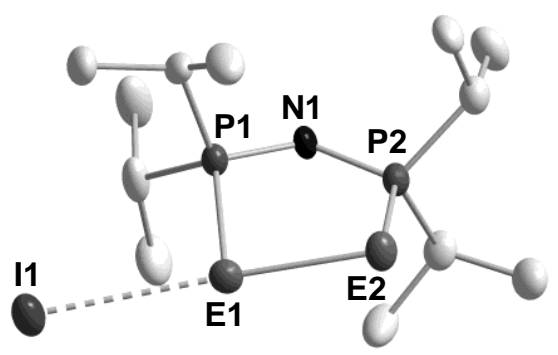

Figure 1. Molecular structures of $4(E=S e)$ and $5(E=T e)$. Hydrogen atoms have been omitted for clarity. Thermal ellipsoids are drawn at $50 \%$ probability level using the structure 4 . Selected bond distances $(\AA)$ and angles $\left({ }^{\circ}\right)$ [calculated values are given in brackets]. 4: Se2-P2 2.229(2) [2.222], P2-N1 1.590(5) [1.618], P1-N1 1.593(5) [1.625], Se1-P1

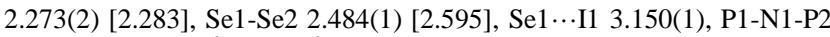
128.3(4) [125.7], | N-P-Se | 108.6 [110.2], $\tau$ P1-Se1-Se2-P2 -25.05(7) [28.6]. 5: Te2-P2 2.436(3) [2.449], P2-N1 1.553(6) [1.616], P1-N1 1.625(6) [1.626], Te1-P1 2.395(3) [2.496], Te1-Te2 2.839(1) [2.884], Te1‥I1 3.430 (1), P1-N1-P2 133.2(4) [129.5], | N-P-Te| 109.5 [111.2], $\tau$ P1-Te1-Te2-P2 -25.84(7) [-27.2].
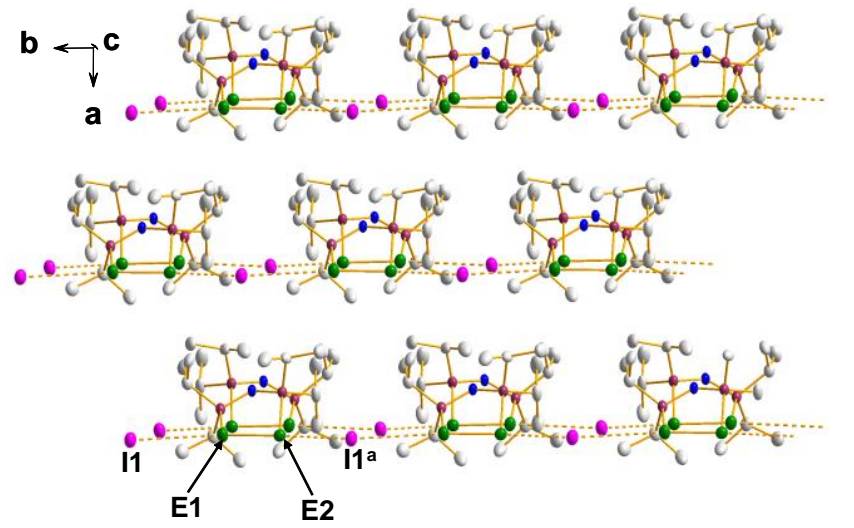

Figure 2. Figure 2. Crystal packing in $4(E=S e)$ and $5(E=T e)$. Hydrogen atoms have been omitted for clarity. Thermal ellipsoids are drawn at $50 \%$ probability level using the structure 4 . E $\cdots$ I close contacts: $\mathrm{Se} 2 \cdots \mathrm{I} 1^{\mathrm{a}} 4.006(1) \AA$ and $\mathrm{Te} 2 \cdots \mathrm{I} 1^{\mathrm{a}} 3.495(1) \AA{ }^{\mathrm{a}}{ }^{\mathrm{a}} \mathrm{x}, \mathrm{y}+1$.

In contrast to the planarity of related chalcogen-nitrogen cations ${ }_{95}\left[\mathrm{RCN}_{2} \mathrm{E}_{2}\right]^{+}(\mathrm{E}=\mathrm{S}, \mathrm{Se}),{ }^{19}\left[\mathrm{E}_{3} \mathrm{~N}_{2}\right]^{2+}(\mathrm{E}=\mathrm{S}, \mathrm{Se}),{ }^{20}$ and the nitrogenrich system $\left[\mathrm{S}_{2} \mathrm{~N}_{3}\right]^{+},{ }^{21}$ the five-membered ring in $\mathbf{4}$ and $\mathbf{5}$ is distinctly puckered (Figure 1). The mean N-P-E bond angles $\left(108.6^{\circ}\right.$ in $\mathbf{4}$ and $109.5^{\circ}$ in 5) are close to the ideal tetrahedral values. The P-N-P bond angles are $128.3(4)^{\circ}$ and $133.2(4)^{\circ}$ in 4 and $100 \mathbf{5}$, respectively. DFT calculations show localization of the positive charge on the phosphorus atoms. ${ }^{22}$ However, the average P-N bond lengths (1.592 $\AA$ in $\mathbf{4}$ and $1.589 \AA$ in 5) are not significantly different from the mean value observed for $2 \mathbf{c} .^{9}$ The chalcogeniodine interactions cause a significant perturbation of the $\mathrm{P}$-E bonds 105 (P-Se: 2.229(2) and 2.273(2) $\AA$ in 4; P-Te: $2.395(3)$ and 2.436(3) in 5, cf. 2.394(2) and 2.489(2) $\AA$ in the neutral ligand $\mathbf{2 c}^{9}$ ). The most interesting structural features of $\mathbf{4}$ and $\mathbf{5}$ are the long E-E bond lengths (2.484(1) $\AA$ in 4 and 2.839(1) $\AA$ in 5), which are ca. 0.14 and $0.10 \AA$ longer than the Se-Se and Te-Te single-bond values. ${ }^{26}$

110 For comparison, the Se-Se bond lengths in the six $\pi$-electron, fivemembered cyclic cations in the salts $\left[\mathrm{PhCN}_{2} \mathrm{Se}_{2}\right]\left[\mathrm{PF}_{6}\right]^{27}$ and $\left[\mathrm{Se}_{3} \mathrm{~N}_{2}\right]\left[\mathrm{AsF}_{6}\right]_{2^{20}}$ are 2.260(5) and 2.253(3) $\AA$, respectively. The
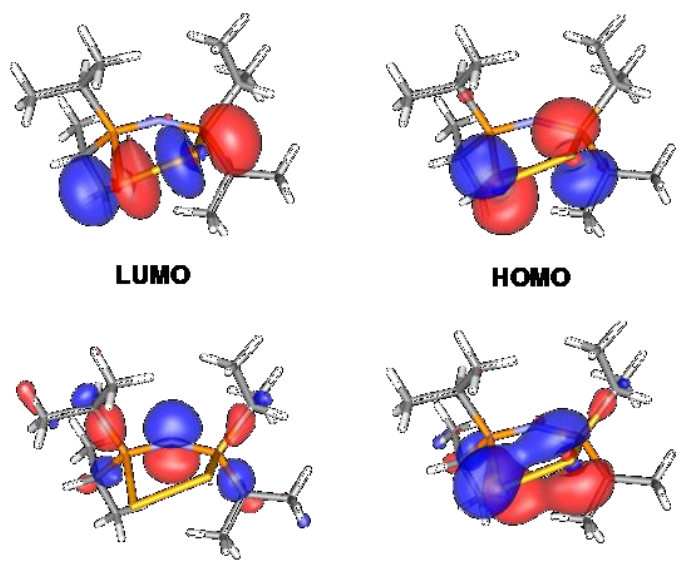

HOMO-1

HOMO-2

Figure 3. Frontier orbitals in the $\left[\mathrm{N}\left(\mathrm{P}^{i} \mathrm{Pr}_{2} \mathrm{E}\right)_{2}\right]^{+}(\mathrm{E}=\mathrm{Se}, \mathrm{Te})$ rings.

Te-Te bond length in the cation $\left[\left(\mathrm{Te}_{2} \mathrm{SN}_{2}\right) \mathrm{Cl}\right]^{+}$, in which one of the Te atoms is three-coordinate, is 2.731(2) $\AA^{28,29}$

115 DFT calculations have provided important insights into the electronic structures in the cyclic cations $\mathbf{3 b}$ and $\mathbf{3 c} .^{22}$ The calculated bond parameters for $\mathbf{4}$ and $\mathbf{5}$ are in reasonable agreement with the observed structural parameters (see caption to Figure 1). The differences in the optimized geometries compared to the 120 observed structures are attributed primarily to the molecular packing interactions observed in the solid state. The three highest occupied molecular orbitals in the five-membered rings $\mathbf{3}$, illustrated in Figure 3, are $\pi$-type orbitals. Thus, although they are non-planar, the cyclic cations are formally six $\pi$-electron systems.

125 The $\pi$-bond order is low, however, since the bonding effect of the E-E $\pi$-bonding orbital (HOMO-2) is essentially cancelled by the double occupation of the E-E $\pi^{*}$-antibonding orbital (HOMO) and the third occupied $\pi$-orbital is primarily non-bonding nitrogencentred orbital (HOMO-1).The long chalcogen-chalcogen bonds in

1304 and 5 are attributed to the donation of electron density from a lone pair on the iodide counter-ion into the $\sigma^{*}$ orbital (LUMO), $c f$. the formation of the triiodide $\mathrm{I}_{3}{ }^{-}$anion from an $\mathrm{I}^{-}$ion and an I-I molecule. ${ }^{30,31}$ DFT calculations confirm this view of the of the E--I interaction. The calculated Te-Te bond lengths for Te---I 135 separations of 3.5, 4.0 and $4.5 \AA$ are 2.880, 2.795 and $2.720 \AA$, respectively.

In summary, the five-membered cyclic cations $\mathbf{3 b}$ and $\mathbf{3 c}$ are the first examples of cations based on the extensively studied EPNPE $(\mathrm{E}=\mathrm{S}, \mathrm{Se}, \mathrm{Te})$ ligand framework. As such they complete the redox 140 sequence $-1 / 0 /+1$ for dichalcogenoimidodiphosphinates. Electrochemical studies of these systems and the synthesis of ionseparated salts are in progress.

\section{Notes and references}

${ }_{145}$ Crystal data for 4: $\mathrm{C}_{12} \mathrm{H}_{28} \mathrm{I}_{1} \mathrm{~N}_{1} \mathrm{P}_{2} \mathrm{Se}_{2}, M_{\mathrm{r}}=533.11$, monoclinic, space group

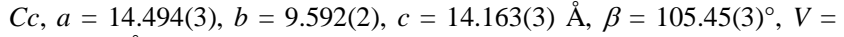
$1897.8(7) \AA^{3}, Z=4, \rho_{\text {calcd }}=1.866 \mathrm{~g} \mathrm{~cm}^{-3}, \mu=5.679 \mathrm{~mm}^{-1}, T=173(2) \mathrm{K}$, 6209 reflections collected $\left(\theta\right.$ range $\left.=4.23-25.02^{\circ}\right), 3258$ unique $\left(R_{\text {int }}=\right.$ $0.0377), R_{1}=0.0348$ [for 3035 reflections with $I>2 \sigma(I)$ ] and $w R_{2}=0.0861$

150 (for all data). Crystal data for 5: $\mathrm{C}_{12} \mathrm{H}_{28} \mathrm{I}_{1} \mathrm{~N}_{1} \mathrm{P}_{2} \mathrm{Te}_{2}, M_{\mathrm{r}}=630.39$, monoclinic, space group $C c, a=14.187(3), b=9.756(2), c=14.682(3)$ $\AA, \beta=108.60(3)^{\circ}, V=1926.0(7) \AA^{3}, Z=4, \rho_{\text {calcd }}=2.174 \mathrm{~g} \mathrm{~cm}^{-3}, \mu=$ $4.786 \mathrm{~mm}^{-1}, T=173(2) \mathrm{K}, 5647$ reflections collected $(\theta$ range $=2.72$ $\left.25.02^{\circ}\right), 3201$ unique $\left(R_{\text {int }}=0.0391\right), R_{1}=0.0317$ [for 2994 reflections 
155 with $I>2 \sigma(I)]$ and $w R_{2}=0.0817$ (for all data). The structure of 5 was disordered containing two overlapping molecules. In the final refinement the main component was $93 \%$ abundant. For the minor $7 \%$ component, only the heaviest atoms (I, Te, P) were located from the density Fourier map. All non-hydrogen atoms in $\mathbf{4}$ and those of the main component in $\mathbf{5}$,

160 were refined with anisotropic thermal parameters. The hydrogen atoms were calculated geometrically and were riding on their respective carbon atoms. The structures were solved by direct methods using SHELXS-97 and the model refined by using SHELXL-97. ${ }^{32}$

The reagent $\left[\mathrm{N}\left(\mathrm{P}^{i} \mathrm{Pr}_{2} \mathrm{Te}\right)_{2}\right]_{2}$ was prepared by the method described 165 earlier ${ }^{9}$ and $\left[(\right.$ tmeda $\left.) \mathrm{NaN}\left(\mathrm{P}^{i} \mathrm{Pr}_{2} \mathrm{E}\right)_{2}\right](\mathrm{E}=\mathrm{Se}, \mathrm{Te})$ were prepared by modifications of the procedure reported for [(tmeda) NaN $\left.\left(\mathrm{PPh}_{2} \mathrm{Te}\right)_{2}\right] .{ }^{8}$

4: A solution of [(tmeda) $\left.\mathrm{NaN}\left(\mathrm{P}^{i} \mathrm{Pr}_{2} \mathrm{Se}\right)_{2}\right](0.273 \mathrm{~g}, 0.50 \mathrm{mmol})$ in toluene $(30 \mathrm{~mL})$ was cooled to $-78{ }^{\circ} \mathrm{C}$ and a cold $\left(0{ }^{\circ} \mathrm{C}\right)$ solution of $\mathrm{I}_{2}$ $(0.127 \mathrm{~g}, 0.50 \mathrm{mmol})$ in THF $(15 \mathrm{~mL})$ was added dropwise via cannula.

170 The resulting red solution was stirred for $1 \mathrm{~h}$ at $-78^{\circ} \mathrm{C}$ and for $2 \mathrm{~h}$ at room temperature. The solvents were removed under vacuum and the residue was dissolved in toluene and then filtered to remove NaI. Toluene was evaporated under vacuum and the resulting powder was washed with $n$ hexane affording 4 as a red, microcrystalline powder $(0.239 \mathrm{~g}, 90 \%)$.

175 Elemental analysis calcd. (\%) for $\mathrm{C}_{12} \mathrm{H}_{28} \mathrm{I}_{1} \mathrm{~N}_{1} \mathrm{P}_{2} \mathrm{Se}_{2}$ : C 27.03, $\mathrm{H} 5.29, \mathrm{~N}$ 2.63; found: C 27.10, H 5.24, N 2.85. ${ }^{1} \mathrm{H}$ NMR (D 8 -THF, $\left.23{ }^{\circ} \mathrm{C}\right): \delta=2.73$ $\left[2 \times\right.$ sept., $\left.{ }^{3} J(\mathrm{H}, \mathrm{H})=7 \mathrm{~Hz}, 4 \mathrm{H} ; \mathrm{CH}\left(\mathrm{CH}_{3}\right)_{2}\right], 1.37\left[\mathrm{dd},{ }^{3} \mathrm{~J}(\mathrm{H}, \mathrm{H})=7 \mathrm{~Hz}\right.$, $\left.{ }^{3} J(\mathrm{H}, \mathrm{P})=18 \mathrm{~Hz}, 12 \mathrm{H} ; \mathrm{CH}\left(\mathrm{CH}_{3}\right)_{2}\right], 1.35\left[\mathrm{dd},{ }^{3} \mathrm{~J}(\mathrm{H}, \mathrm{H})=7 \mathrm{~Hz},{ }^{3} J(\mathrm{H}, \mathrm{P})=20\right.$ $\left.\mathrm{Hz}, 12 \mathrm{H} ; \mathrm{CH}\left(\mathrm{CH}_{3}\right)_{2}\right] ;{ }^{13} \mathrm{C}\left\{{ }^{1} \mathrm{H}\right\}$ NMR: $\delta=33.2\left(\mathrm{~m}, 4 \mathrm{C} ; \mathrm{CH}\left(\mathrm{CH}_{3}\right)_{2}\right), 18.6$ $180\left(\mathrm{~s}, 4 \mathrm{C} ; \mathrm{CH}\left(\mathrm{CH}_{3}\right)_{2}\right), 17.7$ (s, 4C; $\left.\mathrm{CH}\left(\mathrm{CH}_{3}\right)_{2}\right) ;{ }^{31} \mathrm{P}\left\{{ }^{1} \mathrm{H}\right\}$ NMR: $\delta=92.9(\mathrm{br}$, $\left.{ }^{1} J\left({ }^{77} \mathrm{Se}, \mathrm{P}\right) \approx 395 \mathrm{~Hz}\right) ;{ }^{77} \mathrm{Se} \mathrm{NMR}: \delta=297\left(\mathrm{br}, \mathrm{d},{ }^{1} J\left({ }^{77} \mathrm{Se}, \mathrm{P}\right) \approx 420 \mathrm{~Hz}\right)$. Yellow, block-like crystals of $\mathbf{4}$ were grown from a THF:toluene solution.

5 from [(tmeda)NaN $\left.\left(\mathbf{P}^{i} \mathbf{P r}_{2} \mathbf{T e}\right)_{2}\right]$ : The salt 5 was obtained as a dark red, crystalline powder $(0.291 \mathrm{~g}, 92 \%)$ from the reaction of 185 [(tmeda) $\left.\mathrm{NaN}\left(\mathrm{P}^{i} \mathrm{Pr}_{2} \mathrm{Te}\right)_{2}\right](0.321 \mathrm{~g}, 0.50 \mathrm{mmol})$ in toluene $(30 \mathrm{~mL})$ with $\mathrm{I}_{2}$ $(0.127 \mathrm{~g}, 0.50 \mathrm{mmol})$ in THF $(15 \mathrm{~mL})$ by using a procedure identical to that described above for 4. Elemental analysis calcd. (\%) for $\mathrm{C}_{12} \mathrm{H}_{28} \mathrm{I}_{1} \mathrm{~N}_{1} \mathrm{P}_{2} \mathrm{Te}_{2}$ : C 22.86, H 4.48, N 2.22; found: C 22.68, H 4.39, N 2.33. ${ }^{1} \mathrm{H}$ NMR $\left(\mathrm{D}_{8}-\mathrm{THF}, 23{ }^{\circ} \mathrm{C}\right): \delta=2.62\left[2 \mathrm{x}\right.$ sept., ${ }^{3} \mathrm{~J}(\mathrm{H}, \mathrm{H})=7 \mathrm{~Hz}, 4 \mathrm{H}$; $\left.190 \mathrm{CH}\left(\mathrm{CH}_{3}\right)_{2}\right], 1.35\left[\mathrm{dd},{ }^{3} J(\mathrm{H}, \mathrm{H})=7 \mathrm{~Hz},{ }^{3} J(\mathrm{H}, \mathrm{P})=18 \mathrm{~Hz}, 12 \mathrm{H} ; \mathrm{CH}\left(\mathrm{CH}_{3}\right)_{2}\right]$, $1.31\left[\mathrm{dd},{ }^{3} \mathrm{~J}(\mathrm{H}, \mathrm{H})=7 \mathrm{~Hz},{ }^{3} \mathrm{~J}(\mathrm{H}, \mathrm{P})=20 \mathrm{~Hz}, 12 \mathrm{H} ; \mathrm{CH}\left(\mathrm{CH}_{3}\right)_{2}\right] ;{ }^{13} \mathrm{C}\left\{{ }^{1} \mathrm{H}\right\}$ NMR: $\delta=33.1\left(\mathrm{~m}, 4 \mathrm{C} ; \mathrm{CH}\left(\mathrm{CH}_{3}\right)_{2}\right), 19.6$ (s, 4C; $\left.\mathrm{CH}\left(\mathrm{CH}_{3}\right)_{2}\right), 18.1$ (br, s, $\left.4 \mathrm{C} ; \mathrm{CH}\left(\mathrm{CH}_{3}\right)_{2}\right) ;{ }^{31} \mathrm{P}\left\{{ }^{1} \mathrm{H}\right\}$ NMR: $\delta=68.0\left(\mathrm{br},{ }^{1} \mathrm{~J}\left({ }^{125} \mathrm{Te}, \mathrm{P}\right) \approx 1035 \mathrm{~Hz}\right)$. Dark red, block-like crystals of $\mathbf{5}$ were grown from a THF:toluene solution.

1955 from $2 c:\left[\mathrm{N}\left(\mathrm{P}^{i} \mathrm{Pr}_{2} \mathrm{Te}\right)_{2}\right]_{2}(0.100 \mathrm{~g}, 0.10 \mathrm{mmol})$ and $\mathrm{I}_{2}(0.026 \mathrm{~g}, 0.10$ $\mathrm{mmol})$ were added to the same flask and then cold $\left(-78{ }^{\circ} \mathrm{C}\right)$ toluene $(30$ $\mathrm{mL}$ ) was introduced via cannula. The resulting dark red solution was stirred for $1 \mathrm{~h}$ at $-78{ }^{\circ} \mathrm{C}$ and for $2 \mathrm{~h}$ at room temperature. The solvent was removed under vacuum affording $\mathbf{5}$ as a dark red powder $(0.113 \mathrm{~g}, 90 \%)$.

1 For reviews of early work, see: C. Silvestru and J. E. Drake, Coord. Chem. Rev., 2001, 223, 117; T. Q. Ly and J. D. Woollins, Coord. Chem. Rev., 1998, 176, 451.

2 H. Rudler, B. Denise, J. R. Gregorio and J. Vaissermann, Chem. 205 Commun., 1997, 229.

3 S. W. Magennis, S. Parsons, A. Corval, J. D. Woollins and Z. Pikramenou, Chem. Commun., 1999, 61.

4 J. G. H. du Preez, K. U. Knabl, L. Krüger and B. J. A. M. van Brecht, Solvent Extr. Ion Exch., 1992, 10, 729.

2105 For selected examples, see: M. Afzall, D. Crouch, M. A. Malik, M. Motevalli, P. O'Brien, J-H. Park and J. D. Woollins, Eur. J. Inorg. Chem., 2004, 171; M. Afzall, K. Ellwood, N.L. Pickett, P. O’Brien, J. Raftrey and J. Waters, J. Mater. Chem., 2004, 14, 1310; J. Waters, D. Crouch, J. Raftery and P. O'Brien, Chem. Mater., 2004, 16, 3289.

2156 D. J. Crouch, P. O'Brien, M. A. Malik, P. J. Skabara and S. P. Wright, Chem. Commun., 2003, 1454.

7 D. Cupertino, D. J. Birdsall, A. M. Z. Slawin and J. D. Woollins, Inorg. Chim. Acta, 1999, 1, 290.

8 G. G. Briand, T. Chivers and M. Parvez, Angew. Chem., 2002, 114, 220 3618; Angew. Chem., Int. Ed., 2002, 41, 3468.

9 T. Chivers, D. J. Eisler, J.S. Ritch and H. M. Tuononen, Angew. Chem., Int. Ed., 2005, 44, 4953.

10 The selenium analogue $\mathbf{2 b}$ has been made in a similar manner, $\mathrm{T}$. Chivers, D. J. Eisler and J. S. Ritch, unpublished results.
22511 Six- and eight-membered $\mathrm{P}(\mathrm{V})-\mathrm{N}-\mathrm{E}(\mathrm{E}=\mathrm{S}, \mathrm{Se})$ rings containing twocoordinate chalcogen atoms are known, including the planar $\left[\mathrm{Et}_{4} \mathrm{P}_{2} \mathrm{~N}_{4} \mathrm{~S}_{2}\right]^{2+}$ dication. ${ }^{12}$ In all these heterocycles the $\mathrm{P}(\mathrm{V})$ atoms are connected to two N neighbors. T. Chivers, A Guide to ChalcogenNitrogen Chemistry 2005, World Scientific Publishing Co. Pte. Ltd., London, p. 260.

12 M. Brock, T. Chivers, M. Parvez and R. Vollmerhaus, Inorg. Chem., 1997, 36, 485.

13 Crystalline samples of $\mathbf{4}$ and $\mathbf{5}$ remained unchanged after exposure to the atmosphere for several weeks, but decompose slowly in solutions in organic solvents.

14 P. S. Pregosin and R. W. Kunz in NMR: Basic Principles and Progress, 1979, 16, 67, Springer Verlag, Heidelberg.

15 R. K. Chadha and J. E. Drake, J. Organomet. Chem., 1986, 299, 331.

16 J. Konu, T. Chivers, R. S. Laitinen and G. Schatte, Acta Crystallogr., 2005, E61, o2251.

17 For a comprehensive review of selenium-iodine contacts, see W-W. du Mont, A. Martens-von Salzen, F. Ruthe, E. Seppälä, G. Mugesh, F. A. Devillanova, V. Lippolis and N. Kuhn, J. Organomet. Chem., 2001, 623, 14; S. Kubiniok, W.-W. du Mont, S. Pohl and W. Saak, Angew. Chem., Int. Ed. Engl., 1988, 27, 431.

18 L. Pauling, The Nature of the Chemical Bond, $3^{\text {rd }}$ ed., Cornell University Press, Ithaca, 1960

19 For a review, see J. M. Rawson, A. J. Banister and I. Lavender, $A d v$. Heterocycl. Chem., 1995, 62, 137.

25020 E. G. Awere, J. Passmore and P. S. White, J. Chem. Soc., Dalton Trans., 1993, 299.

21 S. Herler, P. Mayer, H. Nöth, A. Schulz, M. Suter and M. Vogt, Angew. Chem., Int. Ed. Engl., 2001, 40, 3173.

22 Mulliken population analysis shows that a significant portion of the 255 positive charge is localized on the phosphorus atoms: $\mathrm{P} 0.23, \mathrm{~N}-0.22$, Se 0.01 in $\mathbf{3 b}$ and $\mathrm{P} 0.30, \mathrm{~N}-0.29$, Te 0.02 in 3c. Computational details: the structures of $\mathbf{3}, \mathbf{4}$, and $\mathbf{5}$ were optimized by using DFT and the hybrid PBE0 exchange-correlation functional. ${ }^{23}$ The calculations utilized the Ahlrichs' triple-zeta valence basis set augmented by one set of polarization functions (TZVP); for tellurium, the corresponding ECP basis set was used. ${ }^{24}$ All calculations were done with the Gaussian 03 program package. ${ }^{25}$

23 J. P. Perdew, K. Burke and M. Ernzerhof, Phys. Rev. Lett., 1996, 77, 3865; J. P. Perdew, K. Burke and M. Ernzerhof, Phys. Rev. Lett., 1997, 78, 1396; J. P. Perdew, M. Ernzerhof and K. Burke, J. Chem. Phys., 1996, 105, 9982.

24 The basis sets were taken from Turbomole basis set library: $\mathrm{ftp} / / / \mathrm{ftp}$. chemie.uni-karlsruhe.de/pub/basen/. Site accessed September 2005.

27025 Gaussian 03, Revision C.02, M. J. Frisch, et al. Gaussian, Inc., Wallingford CT, 2004.

26 The sum of the covalent radii is $2.34 \AA$ for Se-Se and $2.74 \AA$ for TeTe. ${ }^{18}$

27 P. D. B. Belluz, A. W. Cordes, E. M. Kristof, P. V. Kristof, S. W. Liblong and R. T. Oakley, J. Am. Chem. Soc., 1989, 111, 9276.

28 A. Haas, J. Kasprowski and M. Pryka, J. Chem. Soc., Chem. Commun., 1992, 1144.

29 Te-Te bond lengths of ditellurides are typically in the range 2.68-2.71 $\AA$, but a value of $2.77 \AA$ has been reported recently for the highly crowded system $\left(\mathrm{PhMe}_{2} \mathrm{Si}_{3} \mathrm{CTe}-\mathrm{TeC}\left(\mathrm{SiMe}_{2} \mathrm{Ph}\right)_{3}\right.$ : T. M. Klapötke, B. Krumm, H. Nöth, J. C. Gálvez-Ruiz, K. Polborn, I. Schwab, and M. Suter, Inorg. Chem., 2005, 44, 5254.

30 The structures of the almost linear anion $\left[\mathrm{Te}_{3} \mathrm{Ph}_{3}\right]^{-}$( Te-Te 2.939(1) and 3.112(1) $\AA$ ) and the bent cation $\left[\mathrm{Te}_{3} \mathrm{Ph}_{3}\right]^{+}(\mathrm{Te}-\mathrm{Te} 2.979(1)$ and 3.049(1) $\AA$ ) have been compared to that of $\mathrm{I}_{3}$ : A. C. Hillier, S-Y. Liu, A. Sella and M. R. J. Elsegood, Angew. Chem Int. Ed. Engl., 1999, 38, 2745; J. Jeske, W. du Mont and P. G. Jones, Angew. Chem. Int. Ed. Engl., 1997, 36, 2219.

31 The Se $\cdots$ I contact of 3.150(1) A exceeds the upper limit of $c a .3 .00$ $290 \AA$ A proposed by du Mont et al. ${ }^{17}$ to distinguish between 'three centerfour electron bonds' and 'secondary bonds'.

32 G. M. Sheldrick, SHELXS-97, Program for Crystal Structure Determination, University of Göttingen, Germany, 1997; G. M. Sheldrick, SHELXL-97, Program for Crystal Structure Refinement, University of Göttingen, Germany, 1997. 